\title{
Soybean Rust: Too Close for Comfort
}

\author{
G. L. Peterson and K. L. Kosta, Organizers
}

DOI: $10.1094 / \mathrm{PD}-89-0663$

Soybean rust, caused by Phakopsora pachyrhizi, has been noted as a serious foliar disease of soybean in Asia, Africa, and Australia, with yield losses reported from 10 to 80\%. P. pachyrhizi was never reported in the Western Hemisphere until 2001, when it was observed for the first time in South America, notably in Brazil, Paraguay, and Argentina. Known for its rapid, windborne spread potential, the establishment of P. pachyrhizi in the Southern Hemisphere attracted the concern of both U.S. plant pathologists and the soybean industry.

In the anticipated arrival of this pathogen in North America, the focus of this symposium was to present an opportunity for attendees to listen to first-hand accounts of the arrival, impact, and control measures implemented by scientists in Africa and South America. Other topics included the USDA soybean breeding program for rust resistance, epidemiological modeling for the potential spread in the United States, and the presentation of the USDA Soybean Rust Strategic Plan. This dynamic Strategic Plan is not presented here but can be read in its up-to-date form on the USDA Animal and Plant Health Inspection Service website: http://www.aphis.usda.gov/ppq/ep/soybean_rust/

During the preparation of these published proceedings, the symposium title, "Soybean Rust: Too Close for Comfort", became obsolete. On 10 November 2004, the USDA confirmed the first case of soybean rust in the United States at a research farm associated with Louisiana State University. It was speculated that the pathogen arrived late-season via the unusually active hurricane season this year. The disease has since been confirmed in Florida, Arkansas, Georgia, Alabama, and Mississippi.

The organizers of this symposium would like to acknowledge the generous support and sponsorship of the United Soybean Board, which made the participation of Dr. Jose Tadashi Yorinori, EMBRAPA, Brazil, and Dr. Clive Levy, CFUZ, Zimbabwe, possible. Travel and participation by Dr. Antonio Ivancovich, INTA, Argentina, was sponsored by Syngenta and Bayer Cropscience. 